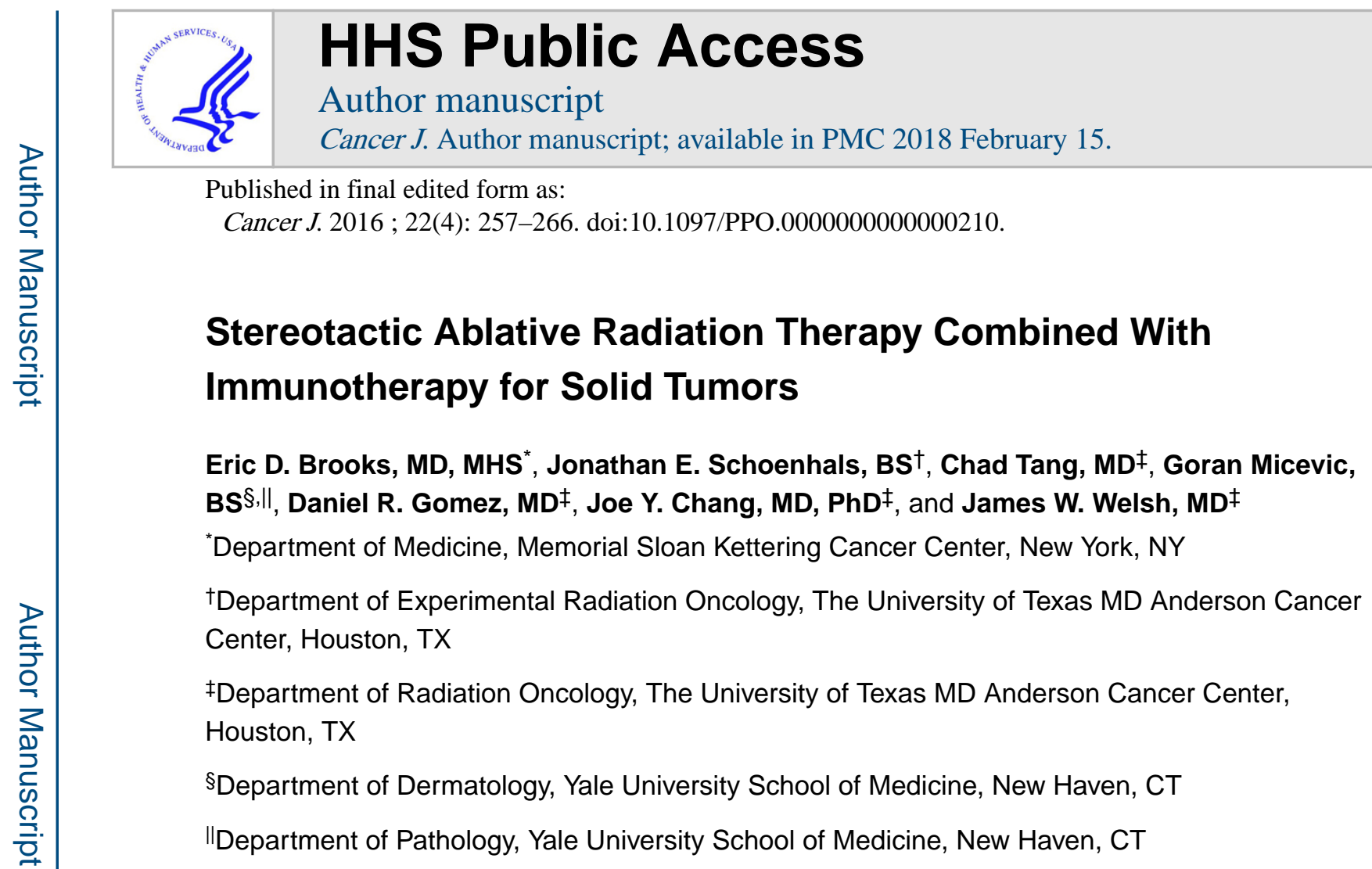

\begin{abstract}
Immunotherapy, particularly immune-checkpoint inhibition, is producing encouraging clinical responses and affecting the way numerous cancers are treated. Yet immune-checkpoint therapy is not effective for many patients, and even those who initially respond can experience relapse, fueling interest in finding new processes or tools to improve the effectiveness of these novel therapeutics. One such tool is radiation. Both preclinical and clinical studies have demonstrated that the systemic effects of immunotherapy can be amplified when it is used in combination with radiation and, conversely, that the immunogenic effects of local irradiation can be amplified and extended to distant sites when used with immunotherapy. We review how stereotactic ablative radiation therapy, a technique specifically indicated for tumors treated with immune-checkpoint inhibitors, can potentiate the effects of immune-checkpoint therapy. We further explore how these novel therapeutics may transform radiation, previously considered a local treatment option, into powerful systemic therapy.
\end{abstract}

\title{
Keywords
}

Abscopal effect; immune-checkpoint inhibitor; ipilimumab; melanoma; nivolumab; non-small cell lung cancer; radiotherapy; stereotactic body radiotherapy

Reprints: James W. Welsh, MD, Department of Radiation Oncology, Unit 97, The University of Texas MD Anderson Cancer Center, 1515 Holcombe Blvd, Houston, TX 77030. jwelsh@ mdanderson.org.

The authors have disclosed that they have no significant relationships with, or financial interest in, any commercial companies pertaining to this article. 


\section{IMMUNOTHERAPY AND RADIATION}

Immunotherapy is transforming the way numerous types of cancer are treated and how oncologists are thinking about the mechanisms of tumor evolution. Immunotherapy acts to empower a patient's immune system, either by releasing the "brakes" that blunt T-cell activity or by blocking the mechanisms developed by tumors to evade immune detection. By doing so, immunotherapeutics, in particular immune-checkpoint inhibitors, are providing encouraging clinical responses that are hoped by many to prove more durable than those evoked by traditional therapeutics.

The first immune-checkpoint inhibitor, ipilimumab, was designed against the naturally occurring immune-inhibitory receptor cytotoxic T-lymphocyte-associated protein 4 (CTLA4) on T cells; ipilimumab activates the immune system and leads to clinically significant reductions in tumor burden. ${ }^{1-3}$ First approved in 2011, ipilimumab became the first drug shown to extend survival in advanced melanoma and has resulted in durable disease control for up to 10 years for some patients, ${ }^{4,5}$ a remarkable achievement for a disease with a prior 5 -year survival rate of close to $10 \%$ to $17 \% .{ }^{3}$ Since that time, ipilimumab is being tested for other types of cancer, including non-small cell lung cancer (NSCLC) (NCT02659059; NCT01285609; NCT02477826), prostate cancer (NCT01377389; NCT01194271; NCT01057810), renal cell carcinoma (RCC) (NCT01472081; NCT02210117; NCT02231749), and others.

Two other checkpoint inhibitors, nivolumab and pembrolizumab, target programmed cell death protein 1 (PD1) receptors on T cells and thereby hinder the ability of tumors to evade immune surveillance by preventing $\mathrm{T}$ cells from interacting with programmed death ligand (PDL) 1 and PDL2, inhibitory ligands, predominantly PDL1, which are overexpressed on tumor cell surfaces. ${ }^{6-8}$ Nivolumab seems to have a better safety profile than ipilimumab ${ }^{9,10}$ and has been approved for treating metastatic melanoma, NSCLC, and recently RCC after extending overall survival for patients with relapsed disease. ${ }^{11-14}$ In fact, current recommendations are that patients with metastatic melanoma or RCC consider enrolling in immunotherapy trials as first-line treatment. ${ }^{15,16}$ Numerous other checkpoint inhibitors, stimulators, and immune modulators are also being developed and tested, including those directed to OX40, ${ }^{17,18}$ TIM-3, ${ }^{19,20}$ ICOS,${ }^{21,22}$ GITR,,${ }^{23,24}$ IDO, ${ }^{25}$ the STAT-3 pathway, ${ }^{26-28}$ and more. ${ }^{29-31}$ The challenge now is to understand how to use these agents in combination with previously approved checkpoint inhibitors, and significant research efforts are focused on how best to combine these drugs with other pillars of oncology—surgery, chemotherapy, and radiation.

Although immunotherapy has produced exciting results to date, unfortunately as of now the vast majority of patients do not respond, and among those who do, some may develop resistant disease. One potential way to improve the effectiveness of immunotherapy may be to combine it with radiation therapy. In 1953, Mole ${ }^{32}$ published the first report of an unexpected, systemic regression of tumor metastasis when local radiation was given to a primary tumor. Mole termed this an "abscopal" effect, derived from the Latin prefix $a b$ ("position away from") and the Greek suffix scopos ("the target"), indicating that the effect took place away from the site of the irradiated tumor. Since then, this rare systemic effect, 
which has been discovered to be mediated by the immune system, ${ }^{33-42}$ has been observed not only in a wide range of tumor types, originally after splenic irradiation for lymphomas and "liquid" cancers, ${ }^{43-46}$ but also in solid tumors after irradiation of the viscera or soft tissues. ${ }^{34,47-54}$ Ways of evoking abscopal effects are now the topic of numerous trials throughout the world. Although preclinical data suggest that local irradiation can have modest immunosuppressive effects such as increasing transforming growth factor $\beta^{55}$ and increasing proportions of regulatory $\mathrm{T}$ cells $\left(\mathrm{T}_{\text {regs }}\right)^{56}$ and myeloid- derived suppressor cells (MDSCs), 57,58 it also has immune-stimulatory effects such as enhancing T-cell priming. 36-41,59-62 Indeed, radiation enhances the immunogenicity of tumors through numerous mechanisms, and this heightened visibility and susceptibility to the immune system cause a high-amplitude local immune response that can then spread and take effect at other, more distant sites when combined with immunotherapy. ${ }^{62-68}$ Although seeing systemic abscopal responses of nonirradiated gross disease is intriguing, this phenomenon remains rare. However, using radiation to help control micrometastatic disease, thereby contributing to important clinical endpoints such as progression-free survival, may be much easier to achieve. ${ }^{69-71}$

Today, two forms of external-beam radiation therapy, each of which may have different antitumor effects, are used in combination with immunotherapy: conventionally fractionated wide-field conformal radiation and stereotactic ablative radiation therapy (SABR).

Conventionally fractionated radiation is the more common type and involves low-dose fractions given once a day (e.g., 10-30 fractions of 1.8-3 Gy each). Stereotactic ablative radiation therapy, on the other hand, involves giving smaller numbers of higher-dose fractions (e.g., 1-5 fractions of 6-30 Gy each).

We review the preclinical and clinical literature on the most effective combinations of radiation therapy with immunotherapy. We focus on SABR in particular because it has been applied mostly to those types of tumors for which immunotherapy has already been approved (metastatic NSCLC, melanoma, and RCC lesions in lung, bone, liver, and lymph nodes). ${ }^{72-77}$ Interestingly, even though high-dose SABR seems to increase the immunostimulatory aspect of T-cell priming — its most profound clinical effect—it may also simultaneously blunt the immune response through increasing the proportions of $\mathrm{T}_{\text {regs }}$ or MDSCs. However, as discussed in the following section, the potentially deleterious effects of radiation may be addressed with immune therapeutics, and thus high-dose SABR seems to be uniquely positioned to combine with immuno-therapy. Our aim is to shed light on how best to combine the various types of radiation with immunotherapy to enhance systemic control, with the ultimate goals of improving future trial design and creating more effective forms of treatment for solid tumors.

\section{RADIATION AND THE IMMUNE SYSTEM}

Many excellent reviews have been published describing the immunogenicity of radiation.

78-82 In brief, radiation improves the immune system's ability to recognize solid tumors by uncovering or releasing previously hidden antigens and immune-stimulatory compounds from within the tumor that can activate and prime an antitumor immune response (Fig. 1). These immune-stimulatory compounds (including "eat me" signals) released include 
calreticulin, adenosine triphosphate, high mobility group box 1 protein, granulocytemacrophage colony-stimulating factor, uric acid, heat shock proteins, and more. ${ }^{83-88}$ These signals, consistent with immunogenic cell death, in conjunction with the release of hidden antigens, prompt the maturation of dendritic cells and other antigen-presenting cells for Tcell activation. ${ }^{85,89}$ Simultaneously, radiation also alters the vascular endothelium of tumor beds and promotes the release of chemokines that allow the immune system to access the tumor. ${ }^{90-92}$ These orchestrated effects culminate in the attraction, invasion, and priming of $\mathrm{CD}^{+} \mathrm{T}$ cells and other effector cells in the tumor microenvironment, which results in significant local antitumor immune destruction. Although radiation also causes a late, secondary reactive attraction of immunosuppressive $\mathrm{T}_{\text {regs }}$ and MDSCs, ${ }^{56-58}$ this is balanced by the immunostimulatory effects and in most cases contributes to a local immune response that can then spread systemically when combined with immune therapy. ${ }^{35-37}$ This effect of radiation is intriguing, because even though immune-checkpoint and modulator therapy can help to overcome barriers to tumor immune evasion or "release the brakes" so that the immune system becomes more hyperactive, the immune system still needs to recognize a tumor as foreign to develop a response of appropriate quality and amplitude to attack the tumor. Radiation thus can be used as a noninvasive tool to promote the necessary steps of priming the immune system against foreign tumor cells, where antigen presentation and costimulation are facilitated against hidden epitopes that—ideally—are shared among distant metastases. Determining which form of radiation (SABR, conventional wide-field radiation, or something else) is most immunogenic will help to optimize how radiation can be best coupled with immune therapy to result in the most powerful antitumor effects.

\section{RADIATION DOSE AND IMMUNOGENICITY}

The oldest information on radiation and immunogenicity comes from in vitro studies of various doses of radiation. Stereotactic ablative radiation therapy involves delivering much higher-dose fractions than does conventional radiation therapy (6-30 Gy vs. 1.8-3 Gy), thus raising the question of which dose per fraction would have the best effects on tumor immunogenicity and activation when given in combination with immunotherapy. In vitro findings suggest that higher doses (consistent with those used in SABR) more effectively enhance immunogenic activity in irradiated tumor cells than do lower doses. ${ }^{63,93,94}$ Specifically, higher doses cause up-regulation of more immune-stimulating factors such as major histocompatibility complex type I (MHC-I), Fas, and intercellular adhesion molecule (ICAM) and more tumor-associated antigens to be presented on the tumor surface, thereby leading to greater immune recognition and destruction (Fig. 2).

In 1 study involving the delivery of 0,10 , or 20 Gy to human colon, lung, and prostate cancer cells in vitro, ${ }^{93}$ the higher doses prompted greater expression of stimulatory immune signals and tumor antigens (Fas, MHC-I, ICAM, carcinoembryonic antigen [CEA], and mucin) on the tumor-cell surfaces, and this greater expression led to more effective immunemediated tumor cell killing. Specifically, higher amounts of CEA antigen expressed on CEA ${ }^{+} / \mathrm{A}^{+}{ }^{+}$colon cancer cells correlated with more tumor death by CEA-specific $\mathrm{CD} 8^{+} \mathrm{T}$ cells. Therefore, radiation was found to have dose-dependent effects on immunogenicity and antitumor immune-cell killing. 
Another in vitro study of human melanoma cells ${ }^{63}$ showed that irradiating with doses of 1 , $4,7,10$, or $25 \mathrm{~Gy}$ also resulted in dose-dependent increases in tumor antigen presentation to T cells via MHC-I. The increase in MHC-I with tumor antigens as a function of increasing radiation dose was particularly striking when doses exceeded $10 \mathrm{~Gy}$ (which is within the dose for SABR) but considerably less so when doses were 4 Gy or less (within the range for conventionally fractionated radiation). Moreover, the radiation-induced increases in MHC-I and associated tumor peptides were not the result of newly made MHC-I, but rather was due to existing MHC-I being expressed as intracellular protein breakdown increased in tumor cells. Therefore, in this study, the higher radiation doses were used to enhance immunogenicity, in part by causing greater protein breakdown within the tumor. In the same report, increases in MHC-I, and the attendant presentation of tumor-associated antigens and immune recognition through MHC-I, were found to result in increased tumor destruction in a MC38 mouse colon adenocarcinoma model. These observations seem to illustrate that higher radiation doses may simply produce greater direct intracellular ionization as opposed to, or in addition to, pathway modulation or transcription and that doses in the SABR range seemed to produce increased tumor immunogenicity and killing.

Other animal studies have also confirmed that higher radiation doses create greater tumor immunogenicity. In 1 such study, ${ }^{95}$ treating a mouse B16 melanoma model with single doses of 5, 7.5, 10, or 15 Gy led to dose-dependent increases in the numbers of tumor-specific, infiltrating $\mathrm{CD}^{+} \mathrm{T}$ cells, which also correlated with improved local tumor control. These findings, that higher-dose radiation fractions function to enhance T-cell infiltration in the tumor microenvironment, also imply that, given the correlation between extent of immune response and local control, improvements in local control from high-dose radiation in the clinic may be, at least in part, immune mediated. This assertion is controversial but is supported by recent evidence that administering immune-suppressing steroids during radiation therapy may, in fact, impair local control. ${ }^{96,97}$ Other preclinical studies indicate that the local control and survival benefits of SABR-like regimens in mouse models are negatively affected when the mice are depleted of $\mathrm{CD}^{+} \mathrm{T}$ cells, ${ }^{71,98}$ suggesting also that an intact immune system is necessary for SABR's local optimal results. The findings of the B16 mouse melanoma study, however, also lend credence to the idea that the increase in immunogenic effects with increasing radiation dose may be dose limiting, in that doses higher than $15 \mathrm{~Gy}$ actually led to poorer $\mathrm{CD}^{+}$tumor infiltration and no increased benefit in local control. Although this finding is not universal across animal studies, it does suggest the existence of an optimal range of high yet sublethal doses that improve immunogenicity and tumor control and that doses higher this range either have no additional benefit or blunt the response. The mechanisms underlying this observation have yet to be revealed.

\section{FRACTIONATION AND IMMUNOGENICITY}

In addition to investigating the effects of high radiation doses on immunogenicity and tumor control, other researchers have compared the effects of single, large-dose fraction regimens that mimic SABR to those of smaller-dose, multifraction schemes that, in some studies, mimic conventional therapy in animal models, with the goal of determining how fractionation, not only dose size, affects tumor-immune interactions. Those studies have generally found that the larger, single-dose regimens are equivalent ${ }^{95}$ or superior $^{98,99}$ to the 
smaller-dose, fractionated regimens in terms of local control and tumor immunogenicity (Fig. 3).

In 1 such study, ${ }^{98}$ a single 20-Gy dose was compared with four 5-Gy fractions in a B16 mouse melanoma model. The single 20-Gy dose produced remarkable local control, with growth delay in $100 \%$ of tumors and complete regression in $35 \%$. In contrast, the regimen of $5 \mathrm{~Gy} \times 4$ fractions had no therapeutic effect. Moreover, mice treated with the 20-Gy regimen had considerably more tumor-infiltrating lymphocytes within the tumors and in the draining lymph nodes. Local control from the high-dose 20-Gy regimen was further found to depend on the presence of $\mathrm{CD} 8^{+} \mathrm{T}$ cells, demonstrating again that the benefits of SABR in clinical practice could be, at least in part, immune mediated. That study revealed that a high-dose, SABR-mimicking regimen produced not only greater local immune effects but also infiltration of $\mathrm{CD}^{+} \mathrm{T}$ cells into lymph nodes. Importantly, in line with in vitro data showing that tumor immunogenicity increases as the size of the dose increases, that study also suggested the existence of a radiation dose threshold that must be reached to achieve meaningful immune-stimulatory effects, because all mice received the same total dose but given in different fractions ( 1 fraction of 20 Gy vs. 4 fractions of 5 Gy), which had profoundly different effects on tumor control and immune infiltration. The apparent existence of a threshold has been found in other studies as well and will be important to consider in designing trials that test whether and how radiation therapy synergizes with immunotherapy in patients with cancer. ${ }^{71,99,100}$

As described in the previous section, 1 study comparing the effects of a single, large-dose fraction ( $15 \mathrm{~Gy}$ ) with those of fractionated regimens (5 fractions of $3 \mathrm{~Gy}$ each, 3 fractions of 5 Gy each, and 2 fractions of 7.5 Gy each) in terms of local tumor control and antitumor immune activation in a $\mathrm{B} 16$ melanoma mouse model $^{78}$ showed that all regimens produced equivalent local tumor control but had different effects on tumor immunogenicity (e.g., the ratio of antitumor $\mathrm{CD}^{+} \mathrm{T}$ cells to immunosuppressive Foxp $3^{+} \mathrm{T}_{\text {regs }}$ in the tumor microenvironment). This was noted despite the presence of a dose-dependent increase in local control and immune activation.

Another study, ${ }^{99}$ in a B16-F0 mouse melanoma model, compared large single-dose irradiation (one 15-Gy fraction) with a more conventional fractionated regimen (five 3-Gy fractions). The single 15-Gy regimen was found to produce (1) significantly greater destruction of tumor cells by antitumor cytotoxic T lymphocytes, (2) greater numbers of activated tumor-specific T cells in draining tumor lymph nodes (anti-OVA CD8 ${ }^{+} \mathrm{T}$ cells), (3) greater quantities of antigen-presenting cells presenting tumor antigen in draining lymph nodes, and (4) greater total numbers of MHC-I-binding immune cells infiltrating the irradiated tumor. Further, adoptive transfer of tumor-specific $\mathrm{T}$ cells led to more $\mathrm{T}$ cells infiltrating and remaining within tumors when the $\mathrm{T}$ cells had been taken from the mice treated with the single 15-Gy dose, whereas the numbers of tumor-specific $\mathrm{T}$ cells decreased over time when they had come from mice treated with the conventionally fractionated regimen. These results indicate that the high-dose, single 15-Gy fraction regimen produced a more durable and longer-lasting antitumor immune memory than did the lower-dose, multifractionated regimen and led to greater immune activation and locally spreading response near the irradiated tumors. 
Several explanations are possible for why lower-dose fractionated regimens were less effective than the single high-dose fraction regimen in some of these studies. One may be that giving repeated low-dose fractions may kill the tumor-infiltrating lymphocytes with every subsequent dose, thereby undermining the $\mathrm{CD}^{+}$antitumor response sought from irradiation. Lymphocytes are known to be exquisitely sensitive to radiation, and repeated dosing, regardless of fractionation (1.8- to 3-Gy fractions vs. 6-to 30-Gy fractions), will deplete the tumor of any existing or new lymphocytes that have infiltrated or migrated to it. 101 Thus, even though lower-dose fractions may prompt an antitumor CD8 ${ }^{+}$response, when the next dose is given, those fresh, antitumor $\mathrm{CD} 8^{+}$populations induced by the previous dose are killed, thereby blunting the entire effect. Evidence in support of this theory comes from a study in which mice implanted with CT26 colon adenocarcinoma cells were given either 1 fraction of $30 \mathrm{~Gy}$ or 10 fractions of $3 \mathrm{~Gy} .{ }^{71}$ Relative to conventionally fractionated therapy, the single, high-dose 30-Gy fractionation resulted in considerably higher tumor control $(90 \%$ vs. $10 \%)$ and survival; however, adding multiple fractions $(3 \mathrm{~Gy} \times 10)$ after a single 30-Gy dose led to a reduction in proportions of antitumor $\mathrm{CD}^{+} \mathrm{T}$ cells from $70 \%$ to $8 \%$. Ultimately, that study demonstrated that $\mathrm{CD} 8^{+}$infiltration and antitumor immunity can be reduced by extended radiation.

Another explanation for the study results, however, may lie in the fact that some studies used doses per fraction that were much lower than optimal for inducing an immune response.

Specifically, both in vitro and animal studies showed that achieving optimal immunogenicity requires radiation doses of $6 \mathrm{~Gy}$ or greater to $8 \mathrm{~Gy},{ }^{39,63,93-95}$ but the studies described previously used only 3- to 5-Gy fractions. Therefore, the differences in results may not have been due to fractionation per se, but rather to the fact that the doses used per fraction were below the threshold necessary to produce a strong immunogenic response. Further studies comparing the effect of radiation dose per fraction on tumor immunogenicity are warranted.

\section{COMBINING RADIATION WITH IMMUNOTHERAPY}

As described in the previous sections, preclinical studies have suggested that larger radiation doses are more immunogenic and provide better local tumor control than smaller doses. Whether this relationship holds true in terms of enhanced systemic antitumor responses when radiation is combined with immunotherapy remains to be seen, with some studies supporting and others refuting this idea. One group, working with a 4T1 mouse breast cancer model, ${ }^{100}$ found that a single 12-Gy fraction coupled with anti-PD1 therapy had a cure rate of $100 \%$ for primary lesions, whereas the cure rate for four 5-Gy fractions was $80 \%$, and that for five $4-G y$ fractions was $40 \%$. Although responses to tumors outside the radiation field were not evaluated in that study, the results nevertheless show a dosedependent relationship between radiation fraction dose size and local tumor control regardless of the total dose delivered, which supports the previous postulate of an immunogenic dose threshold. The improvement in local control from anti-PD1 and radiation in this study could result from several mechanisms. Some in vivo results suggest that although high-dose radiation overall tilts the tumor microenvironment to a proimmune stimulatory state, it also recruits larger numbers of immune-inhibitory MDSCs. ${ }^{58,102-105}$ Myeloid-derived suppressor cell recruitment is associated with suppression of antitumor T cells, both immediately after irradiation and subsequently with late-onset local relapse and 
blunting of radiation-induced antitumor immune response. ${ }^{105,106}$ The addition of anti-PD1 can reduce the numbers of MDSCs after irradiation, in addition to blocking tumor-induced T-cell suppression through MDSC PDL1 expression and therefore can enhance radiationinduced immune-stimulatory effects. ${ }^{107-110}$ Understanding how immune-checkpoint modulators can dampen the late immune-suppressive component of the local radiation response in a way that tilts it further toward a proimmune stimulatory environment is an area of ongoing investigation. ${ }^{107}$

Subsequent studies of how fractionation affects the systemic effects of immunotherapy also showed that higher-dose regimens enhance the ability of immunotherapy to act distantly in addition to enhancing local control. However, those studies also showed that giving highdose fractionated radiation —in other words, keeping the dose per fraction high ( $\ 6-8 \mathrm{~Gy}$ ) but changing the number of fractions-led to still better systemic antitumor responses compared with single high-dose therapy. In this early comparison of single high-dose therapy with multiple high-dose therapy (one 20-Gy fraction vs. three 8-Gy fractions vs. five 6-Gy fractions), multiple high-dose therapy was found to produce superior results when combined with immunotherapy.

The first of these studies ${ }^{111}$ involved a $4 \mathrm{~T} 1$ mouse breast cancer model treated with either one 12-Gy fraction or 2 12-Gy fractions plus anti-CTLA4 immunotherapy. Because 4T1 mouse breast cancer cells spontaneously metastasize to the lungs, this study was designed to evaluate whether radiation with anti-CTLA4 would act synergistically to blunt or eradicate metastases. Both radiation schedules (given to the primary tumor lesion) significantly decreased the numbers of lung metastases and substantially extended survival of the mice, but the 2 -fraction regimen was superior in decreasing micrometastatic lung disease and improving survival. Previous studies had evaluated only single high-dose fractions versus multiple low-dose fractions for superiority, so that the study was the first to test and show that multiple high-dose fractions were superior to a single high-dose fraction for enhancing immunogenicity. That same group also noted that the reduction in metastatic disease occurred only when radiation was combined with anti-CTLA4, illustrating that the combination is necessary for an effective systemic response. As mentioned previously, even though CTLA4 immunotherapy "releases the brakes" on the immune system, the immune system still needs to recognize a portion of the tumor as foreign, and radiation's ability to increase tumor antigen release and modulate the tumor microenvironment to allow both visibility of the tumor and access to it may provide this necessary step. That same study found that the distant antitumor effects depended on $\mathrm{CD} 8^{+} \mathrm{T}$ cells, but not $\mathrm{CD} 4^{+} \mathrm{T}$ cells, a finding in agreement with other preclinical results suggesting that the enhanced systemic, immune-mediated effects of radiation are, in part or wholly, mediated by cytotoxic $\mathrm{T}$ lymphocytes. ${ }^{35,111,112}$ Given the promising results of this first study, the same group subsequently tested various dose and fraction combinations to see, which would best enhance distant immune response in bulky disease. ${ }^{39}$ Two models were evaluated for systemic tumor regression, one with TSA breast cancer cells and the other with MC38 colon cancer cells. In both models, a primary tumor and a secondary tumor were implanted on either flank. The primary tumor was then locally irradiated with one 20-Gy fraction, three 8Gy fractions, or five 6-Gy fractions (the latter two consistent with clinical SABR regimens), with the assumption that the higher doses would be more immunogenic. Anti-CTLA4 was 
given after the irradiation, and responses of the irradiated primary tumor and the nonirradiated secondary tumor were both evaluated, the former for local response and the latter for distant (abscopal) response. The single 20-Gy fraction was as effective as the other 2 fractionation schedules in controlling the growth of the locally irradiated tumor. However, in terms of eliciting a distant immune response in the secondary, nonirradiated tumor site, only the fractionated schedules (three 8-Gy or five 6-Gy fractions) enhanced the systemic effects of anti-CTLA4. Moreover, the three 8-Gy schedule produced a considerably more exaggerated abscopal response and tumor regression than did the five 6-Gy schedule. Finally, the one 20-Gy fraction schedule had some synergistic effects with immunotherapy in producing a distant abscopal response in the MC38 model, but it did not produce an abscopal response in the TSA model.

Next, these investigators sought to determine the reasons for the success of the three 8-Gy schedule in producing an abscopal response in both experiments. They found that the three 8-Gy fraction group had more $\mathrm{CD} 8^{+}$tumor-infiltrating lymphocytes in the nonirradiated secondary (abscopal) tumors in the $8 \mathrm{~Gy} \times 3$ fraction regimen than did the other fractionation groups and that more antitumor, cytotoxic $\mathrm{T}$ cells (interferon $\gamma$ producing $\mathrm{CD} 8^{+} \mathrm{T}$ cells) were present in the spleens of mice treated with three 8-Gy fractions that had an abscopal response. Therefore, although the question of how was not answered completely (e.g., through increased tumor antigen presentation, chemokine release, vascular changes, or costimulatory signal presentation), the observation that three 8-Gy fractions led to enhanced immune dissemination and infiltration of the secondary nonirradiated tumor did confirm that the optimal clinical response resulted from the superior immunogenic effects of that fractionation schedule. This second study, the only one to date to combine radiation and immunotherapy and look at the effect of fractionation on abscopal responses in bulky disease, showed that several large-dose fractions $(8 \mathrm{~Gy} \times 3)$ were superior to a single highdose fraction in producing an abscopal response, echoing the results of that group's previous study showing that 2 high-dose fractions $(12 \mathrm{~Gy} \times 2)$ were superior to 1 high-dose fraction $(12 \mathrm{~Gy} \times 1)$. Specifically, the single high-dose fraction did eradicate some micrometastases in the previous 4T1 study and had produced some abscopal response in the MC38 model; it had no effect in the TSA model, a finding that probably reflects the variability inherent in the tumor models but also suggests that radiation may work better in synergy with immunotherapy to eradicate micrometastatic disease rather than gross disease, an interpretation supported by clinical ${ }^{70}$ and by preclinical findings. ${ }^{71}$ Also, these studies used only anti-CTLA4 immunotherapy, and further studies are needed to assess dose size and fractionation in combination with other immunotherapy agents. The immunogenic effects of radiation seem to be carried out during the priming stage of the antitumor immune response. Because each of the numerous immunotherapy modulators acts at different immune checkpoints or pathways, and therefore at different stages of an antitumor response, it is likely that they will couple with radiation differently as well.

Finally, previous studies indicating that a single high-dose fraction schedule was quite immunogenic, more so than a lower-dose (3-5 Gy) fractionated schedule, evaluated the effects of these 2 regimens only on the primary irradiated tumor, and a single high-dose schedule was not compared with moderately high-dose hypofractionated therapy (with fractions in the 6- to 8-Gy range). Findings from the 2 studies described previously seem to 
indicate that a single high-dose fraction is as effective as a moderately high-dose ( $\ 6 \mathrm{~Gy}$ ) schedule for controlling the local irradiated tumor when combined with anti-CTLA4 immunotherapy. However, the story changes when the focus is on the response of lesions away from the primary site. Although extended radiation schedules may not be optimal in terms of an immunogenic response, fractionated therapy does produce drastically different tumor gene expression patterns than does single-dose therapy. ${ }^{113}$ Recent findings that fractionated therapy increased overall gene expression in tumor cells to a greater extent than did single high-dose therapy revealed that some of the genes that were "turned on" were immunostimulatory, and others were immunoinhibitory. ${ }^{114-118}$ Although the study was not designed to test how gene expression changes would affect tumor immunogenicity, the results nevertheless illustrate that fractionated radiation affects tumor phenotypes in quite different ways than does single-fraction high-dose radiation and in ways that interact with genes involving the host immune system. Therefore, the benefits from fractionated radiation relative to single high-dose radiation may be related to the different ways in which shortcourse fractionated radiation affects both the tumor and the microenvironmental phenotype compared with single-dose therapy. Studies are needed to quantify the changes induced by each type of radiation therapy and to reveal the pathways that might be targeted to bolster the superior immunostimulatory effects of short-course fractionated radiation compared with single high-dose or extended low-dose radiation seen in these experiments.

Ultimately, the study that directly compared single high-dose radiation to multiple high-dose radiation regimens showed that fractionated high-dose regimens (consistent with those used clinically for SABR) may be the best to use in combination with immunotherapy. The fact that the three 8-Gy fraction schedule was superior to the five 6-Gy fraction schedule is consistent with previous in vitro and in vivo data showing that larger fraction dose size (6-8 Gy) is more immunogenic and that more extended, fractionated radiation is inferior to or interferes with a strong immunogenic effect (i.e., that 5 fractions would be inferior to 3 fractions). More studies corroborating these findings are needed, as are studies comparing these SABR-like regimens with conventional, lower-dose regimens (e.g., ten 3-Gy fractions) to fully flesh out all the potential comparisons.

\section{CLINICAL OUTCOMES AFTER RADIATION AND IMMUNOTHERAPY}

To date, almost all case reports demonstrating an abscopal effect from combining radiation and immunotherapy have used SABR or SABR-like dosing regimens (e.g., 1-5 fractions of \6 Gy). ${ }^{33,34,47,119-121}$ At least 1 small series of abscopal effect after stereotactic body radiotherapy (SBRT) alone has been reported for metastatic renal cell cancer, ${ }^{122}$ and a phase I study of SBRT and interleukin 2 for renal cell cancer or melanoma revealed a $67 \%$ response rate in nonirradiated lesions with that combination. ${ }^{123}$ At least 6 cases have been reported of abscopal effects in melanoma and NSCLC after treatment with checkpoint inhibitors and radiation. The first such case, reported in $2012,{ }^{34}$ heightened interest in examining how radiation could be coupled with immunotherapy after a 33-year-old woman with metastatic melanoma had experienced abscopal effects after receiving ipilimumab with radiation. That woman had received SABR (three 9.5-Gy fractions) to a paraspinal mass in the thorax, with ipilimumab given both before and after the radiation. That treatment produced a complete response that persisted as no evidence of disease for a year afterward. 
Subsequently, another abscopal response was reported in a man with metastatic melanoma who received ipilimumab both before and after SBRT to a liver lesion. ${ }^{119}$ That man also experienced a complete response. Another patient with metastatic melanoma was given three 8-Gy fractions of 6-MeV electrons to a primary scalp lesion, followed by brain stereotactic radio-surgery and ipilimumab. ${ }^{33}$ That treatment also produced a complete response, with regression of all systemic diseases. A year later, in 2013, the first report of an abscopal response to metastatic NSCLC appeared. ${ }^{120}$ That report involved a 64-year-old man who received high-dose hypofractionated radiation (five 6-Gy fractions, delivered with intensitymodulated radiation therapy) to a liver metastasis with concurrent ipilimumab; that patient also experienced complete response. Other cases of abscopal effects in patients receiving immunotherapy with SABR or stereotactic radiosurgery also have been reported since that time. ${ }^{47,119}$

These case reports of abscopal effects with radiation plus immunotherapy mirror the preclinical findings that relatively few fractions of relatively high radiation doses produce the desired systemic effects. Notably, in most cases, the irradiated lesions were visceral rather than bony or nonvisceral lesions. Thus, the location, and thus the microenvironment, of the tumor being irradiated probably has significant effects on the biology of the interaction on radiation with immunotherapy, and hence selection of the site to be irradiated may be equally important as the choice of radiation dose and fractionation. ${ }^{124}$ The fact that almost all reported abscopal cases with immune therapy have involved SABR or stereotactic radiosurgery-like regimens, however, strongly supports combining SABR regimens with immunotherapy to achieve abscopal responses.

When this review was written, only 1 phase III trial evaluating the efficacy of immunotherapy and radiation had been published. In that trial, men with advanced, castrateresistant prostate cancer were given one 8-Gy fraction of wide-field radiation to a single bony metastasis followed by ipilimumab or placebo. Although the primary analysis of all participants in this trial found no improvement in overall survival, overall survival and progression-free survival increased, and prostate-specific antigen levels dropped by greater than $50 \%$, among men with favorable prognostic factors (i.e., alkaline phosphatase concentration $<1.5$ times the upper limit of normal, hemoglobin concentration of $\geq 110 \mathrm{~g} / \mathrm{L}$, and no visceral metastases) who had received radiation with ipilimumab. ${ }^{70}$ Before that report, the safety and antitumor activity of ipilimumab with or without radiation for metastatic prostate cancer were tested in a phase I/II trial. ${ }^{125}$ In that study, 77 patients received ipilimumab, either alone or with radiation in the same regimen as in the phase III trial ( 1 fraction of $8 \mathrm{~Gy}$, given as wide-field irradiation, to a single bony metastasis). That combination therapy was found to be safe, and the addition of radiation to ipilimumab was found to produce higher rates of stable disease (25\% vs. $13 \%$ for ipilimumab alone) and lower rates of disease progression ( $25 \%$ vs. $38 \%$ ) at a mean follow-up time of 15.7 months. Thus, results of a primary analysis of the single phase III trial conducted to date did not show an overall difference, but a subgroup of men with prostate cancer seemed to benefit from the combination therapy. This benefit was observed in patients with lower burdens of disease (no visceral metastases), which supports the notion that radiation and immunotherapy may act best to eradicate micrometastatic disease rather than bulky disease. Preclinical findings and previous reports of abscopal effects suggest that the phase III study 
results might have been more positive if the investigators had targeted primary visceral lesions for irradiation, used multiple high-dose fractions rather than a single high-dose fraction, and included patients with nonoligometastatic disease. Future studies of the best ways to enhance systemic effects through the combination of radiation and immunotherapy will benefit greatly from these results. However, conclusive phase III studies demonstrating synergistic effects of radiation therapy and immunotherapy for metastatic disease are still eagerly awaited.

Several trials of SABR combined with immunotherapy are ongoing at MD Anderson Cancer Center. One phase I/II trial, NCT02239900, is investigating ipilimumab in combination with SABR (total dose $50 \mathrm{~Gy}$ in four 12.5-Gy fractions or $60 \mathrm{~Gy}$ in ten 6-Gy fractions) to lung or liver lesions. Preliminary results from the phase I portion of that trial, to be presented at the 2016 annual meeting of the American Society of Radiation Oncology, indicate that all treatment combinations for which full enrollment has been reached are safe, ${ }^{126}$ and instances of disease response outside the radiation field have also been observed. The phase I portion of this trial is now complete, and patients are currently being enrolled to the phase II portion to provide further data on efficacy.

\section{SUMMARY}

Overall, preliminary findings to date suggest that SABR may be particularly well positioned to couple with immuno-therapy. Although additional studies are needed, preclinical findings indicate that larger doses per fraction, consistent with those delivered by SABR (i.e., >6-8 Gy), may be the most immunogenic, providing the greatest enhancement of local antitumor immune response, and, when given with immune-checkpoint inhibitors, provide the greatest synergy for producing systemic tumor regression. ${ }^{39,63,93,94,98-100,111}$ Improved responses to higher-dose fractions may be the result of several mechanisms, including increased protein breakdown and consequent tumor antigen and MHC-I presentation as well as modulating the tumor and its microenvironment to attract and activate greater numbers of antitumor lymphocytes (increased ICAM, MHC-I, tumor antigens). Although a single fraction of highdose radiation has produced superior results compared with lower or conventional-dose fractionated therapy in many preclinical studies, fractionated high-dose therapy seems to provide the greatest benefit when coupled with immune-checkpoint inhibition. ${ }^{39}$ The superiority of fractionated high-dose, but not fractionated low-dose, radiation supports the theory that a certain dose threshold level may need to be reached for radiation to be effectively coupled with immunotherapy. These findings also suggest that using a limited number of fractions after that dose threshold is reached may have immunogenic benefits and that fractionated radiation has profoundly different effects from single-dose radiation in modulating immune-directed genes within the tumor. ${ }^{113}$ Thus, although extended low-dose radiation may have a depleting effect on antitumor immune-cell numbers and response, a short course of high-dose radiation does not seem to have the same negative effect. However, this supposition should be confirmed in studies comparing immunotherapy with low-dose extended fractionated therapy in animal models and in patients. Additional investigations are needed to understand the principles and mechanisms behind this and other observed radiation-immune system interactions. 
Finally, most reports to date about abscopal effects from immune-checkpoint inhibitors have occurred with SABR or SABR-like regimens, and numerous clinical and laboratory trials are ongoing to reveal the optimal form of radiation to combine with current and future "new age" immunotherapies. Although we focused in this review on immune-checkpoint inhibitors (anti-CTLA4 and anti-PD1), other immunotherapies such as chimeric antigen receptor T cells, ${ }^{127-129}$ various immune "vaccines" (including oncolytic viruses), ${ }^{130-133}$ and others are in the early stages of development. If other such therapies are successful, then studies of radiation combined with those therapies are expected to emerge. At present, most of the evidence to support radiation synergizing with immunotherapy comes from preclinical models and anecdotal case reports; thus, clinical trials of patients with a variety of types of cancer are needed to definitively demonstrate the benefit of radiation in combination with immunotherapy in practice. Nevertheless, tantalizing evidence suggests that SABR shows great promise for combining with current and future immunotherapy regimens for the treatment of solid tumors.

\section{Acknowledgments}

Supported in part by Cancer Center Support (Core) grant CA016672 from the National Cancer Institute; National Institutes of Health grant to The University of Texas MD Anderson Cancer Center; The family of M. Adnan Hamed; The Mabuchi Research Fund; The Susan and Peter Goodwin Foundation; and the Orr Family Foundation to MD Anderson Cancer Center's Thoracic Radiation Oncology Program, an MD Anderson Knowledge Gap Award.

\section{References}

1. Leach DR, Krummel MF, Allison JP. Enhancement of antitumor immunity by CTLA-4 blockade. Science. 1996; 271:1734-1736. [PubMed: 8596936]

2. Krummel MF, Allison JP. CD28 and CTLA-4 have opposing effects on the response of T cells to stimulation. J Exp Med. 1995; 182:459-465. [PubMed: 7543139]

3. Hodi FS, O'Day SJ, McDermott DF, et al. Improved survival with ipilimumab in patients with metastatic melanoma. N Engl J Med. 2010; 363:711-723. [PubMed: 20525992]

4. Schadendorf D, Hodi FS, Robert C, et al. Pooled analysis of long-term survival data from phase II and phase III trials of ipilimumab in unresectable or metastatic melanoma. J Clin Oncol. 2015; 33:1889-1894. [PubMed: 25667295]

5. Prieto PA, Yang JC, Sherry RM, et al. CTLA-4 blockade with ipilimumab: long-term follow-up of 177 patients with metastatic melanoma. Clin Cancer Res. 2012; 18:2039-2047. [PubMed: 22271879]

6. Dong H, Strome SE, Salomao DR, et al. Tumor-associated B7-H1 promotes T-cell apoptosis: a potential mechanism of immune evasion. Nat Med. 2002; 8:793-800. [PubMed: 12091876]

7. Blank C, Brown I, Peterson AC, et al. PD-L1/B7H-1 inhibits the effector phase of tumor rejection by $\mathrm{T}$ cell receptor (TCR) transgenic $\mathrm{CD}^{+}{ }^{+} \mathrm{T}$ cells. Cancer Res. 2004; 64:1140-1145. [PubMed: 14871849]

8. Taube JM, Anders RA, Young GD, et al. Colocalization of inflammatory response with B7-H1 expression in human melanocytic lesions supports an adaptive resistance mechanism of immune escape. Sci Transl Med. 2012; 4:127ra37.

9. Topalian SL, Hodi FS, Brahmer JR, et al. Safety, activity, and immune correlates of anti-PD-1 antibody in cancer. N Engl J Med. 2012; 366:2443-2454. [PubMed: 22658127]

10. Larkin J, Chiarion-Sileni V, Gonzalez R, et al. Combined nivolumab and ipilimumab or monotherapy in untreated melanoma. N Engl J Med. 2015; 373:23-34. [PubMed: 26027431]

11. Motzer RJ, Escudier B, McDermott DF, et al. Nivolumab versus evero-limus in advanced renal-cell carcinoma. N Engl J Med. 2015; 373:1803-1813. [PubMed: 26406148] 
12. Brahmer J, Reckamp KL, Baas P, et al. Nivolumab versus docetaxel in advanced squamous-cell non-small-cell lung cancer. N Engl J Med. 2015; 373:123-135. [PubMed: 26028407]

13. Weber JS, D'Angelo SP, Minor D, et al. Nivolumab versus chemotherapy in patients with advanced melanoma who progressed after anti-CTLA-4 treatment (CheckMate 037): a randomised, controlled, open-label, phase 3 trial. The Lancet Oncology. 2015; 16:375-384. [PubMed: 25795410]

14. Robert C, Long GV, Brady B, et al. Nivolumab in previously untreated melanoma without BRAF mutation. N Engl J Med. 2015; 372:320-330. [PubMed: 25399552]

15. [Accessed February 1, 2016] NCCN Clinical Practice Guidelines in Oncology. Melanoma. Available at: http://www.nccn.org/professionals/physician_gls/PDF/melanoma.pdf

16. [Accessed February 1, 2016] NCCN Clinical Practice Guidelines in Oncology: Kidney Cancer. Available at: http://www.nccn.org/professionals/physician_gls/pdf/kid-ney_blocks.pdf

17. Curti BD, Kovacsovics-Bankowski M, Morris N, et al. OX40 is a potent immune-stimulating target in late-stage cancer patients. Cancer Res. 2013; 73:7189-7198. [PubMed: 24177180]

18. Rogers PR, Song J, Gramaglia I, et al. OX40 promotes Bcl-xL and Bcl-2 expression and is essential for long-term survival of CD4 T cells. Immunity. 2001; 15:445-455. [PubMed: 11567634]

19. Anderson AC. Tim-3: an emerging target in the cancer immunotherapy landscape. Cancer Immunol Res. 2014; 2:393-398. [PubMed: 24795351]

20. Sanchez-Fueyo A, Tian J, Picarella D, et al. Tim-3 inhibits T helper type 1-mediated auto- and alloimmune responses and promotes immunological tolerance. Nat Immunol. 2003; 4:1093-1101. [PubMed: 14556005]

21. Wang S, Zhu G, Chapoval AI, et al. Costimulation of T cells by B7-H2, a B7-like molecule that binds ICOS. Blood. 2000; 96:2808-2813. [PubMed: 11023515]

22. Hutloff A, Dittrich AM, Beier KC, et al. ICOS is an inducible T-cell co-stimulator structurally and functionally related to CD28. Nature. 1999; 397:263-266. [PubMed: 9930702]

23. Ko K, Yamazaki S, Nakamura K, et al. Treatment of advanced tumors with agonistic anti-GITR $\mathrm{mAb}$ and its effects on tumor-infiltrating Foxp $3^{+} \mathrm{CD} 25^{+} \mathrm{CD} 4^{+}$regulatory T cells. J Exp Med. 2005; 202:885-891. [PubMed: 16186187]

24. Shimizu J, Yamazaki S, Takahashi T, et al. Stimulation of CD25(+)CD4(+) regulatory T cells through GITR breaks immunological self-tolerance. Nat Immunol. 2002; 3:135-142. [PubMed: 11812990]

25. Uyttenhove C, Pilotte L, Theate I, et al. Evidence for a tumoral immune resistance mechanism based on tryptophan degradation by indoleamine 2,3-dioxygenase. Nat Med. 2003; 9:1269-1274. [PubMed: 14502282]

26. Yu H, Kortylewski M, Pardoll D. Crosstalk between cancer and immune cells: role of STAT3 in the tumour microenvironment. Nat Rev Immunol. 2007; 7:41-51. [PubMed: 17186030]

27. Yu H, Pardoll D, Jove R. STATs in cancer inflammation and immunity: a leading role for STAT3. Nat Rev Cancer. 2009; 9:798-809. [PubMed: 19851315]

28. Wang T, Niu G, Kortylewski M, et al. Regulation of the innate and adaptive immune responses by Stat-3 signaling in tumor cells. Nat Med. 2004; 10:48-54. [PubMed: 14702634]

29. Sharma P, Allison JP. The future of immune checkpoint therapy. Science. 2015; 348:56-61. [PubMed: 25838373]

30. Pardoll DM. The blockade of immune checkpoints in cancer immunotherapy. Nat Rev Cancer. 2012; 12:252-264. [PubMed: 22437870]

31. Topalian SL, Drake CG, Pardoll DM. Immune checkpoint blockade: a common denominator approach to cancer therapy. Cancer Cell. 2015; 27:450-461. [PubMed: 25858804]

32. Mole RH. Whole body irradiation; radiobiology or medicine? Br J Radiol. 1953; 26:234-241. [PubMed: 13042090]

33. Stamell EF, Wolchok JD, Gnjatic S, et al. The abscopal effect associated with a systemic antimelanoma immune response. Int J Radiat Oncol Biol Phys. 2013; 85:293-295. [PubMed: 22560555] 
34. Postow MA, Callahan MK, Barker CA, et al. Immunologic correlates of the abscopal effect in a patient with melanoma. N Engl J Med. 2012; 366:925-931. [PubMed: 22397654]

35. Demaria $\mathrm{S}, \mathrm{Ng} \mathrm{B}$, Devitt ML, et al. Ionizing radiation inhibition of distant untreated tumors (abscopal effect) is immune mediated. Int J Radiat Oncol Biol Phys. 2004; 58:862-870. [PubMed: 14967443]

36. Hodge JW, Sharp HJ, Gameiro SR. Abscopal regression of antigen disparate tumors by antigen cascade after systemic tumor vaccination in combination with local tumor radiation. Cancer Biother Radiopharm. 2012; 27:12-22. [PubMed: 22283603]

37. Chakraborty M, Abrams SI, Coleman CN, et al. External beam radiation of tumors alters phenotype of tumor cells to render them susceptible to vaccine-mediated T-cell killing. Cancer Res. 2004; 64:4328-4337. [PubMed: 15205348]

38. Yasuda K, Nirei T, Tsuno NH, et al. Intratumoral injection of interleukin-2 augments the local and abscopal effects of radiotherapy in murine rectal cancer. Cancer Sci. 2011; 102:1257-1263. [PubMed: 21443690]

39. Dewan MZ, Galloway AE, Kawashima N, et al. Fractionated but not single-dose radiotherapy induces an immune-mediated abscopal effect when combined with anti-CTLA-4 antibody. Clin Cancer Res. 2009; 15:5379-5388. [PubMed: 19706802]

40. Akutsu Y, Matsubara H, Urashima T, et al. Combination of direct intra-tumoral administration of dendritic cells and irradiation induces strong systemic antitumor effect mediated by GRP94/gp96 against squamous cell carcinoma in mice. Int J Oncol. 2007; 31:509-515. [PubMed: 17671676]

41. Mikuriya S, Hatano K, Konoeda K, et al. Study of abscopal effect and cellular infiltration of tumor nests using less-fractionated, large-dose radiation [in Japanese]. Gan No Rinsho. 1987; 33:1239_ 1252. [PubMed: 3669314]

42. Finkelstein SE, Rodriguez F, Dunn M, et al. Serial assessment of lymphocytes and apoptosis in the prostate during coordinated intraprostatic dendritic cell injection and radiotherapy. Immunotherapy. 2012; 4:373-382. [PubMed: 22512631]

43. Antoniades J, Brady LW, Lightfoot DA. Lymphangiographic demonstration of the abscopal effect in patients with malignant lymphomas. Int J Radiat Oncol Biol Phys. 1977; 2:141-147. [PubMed: 403163]

44. Rees GJ. Abscopal regression in lymphoma: a mechanism in common with total body irradiation? Clin Radiol. 1981; 32:475-480. [PubMed: 7249526]

45. Nobler MP. The abscopal effect in malignant lymphoma and its relationship to lymphocyte circulation. Radiology. 1969; 93:410-412. [PubMed: 5822721]

46. Sham RL. The abscopal effect and chronic lymphocytic leukemia. Am J Med. 1995; 98:307-308. [PubMed: 7872349]

47. Okwan-Duodu D, Pollack BP, Lawson D, et al. Role of radiation therapy as immune activator in the era of modern immunotherapy for metastatic malignant melanoma. Am J Clin Oncol. 2015; 38:119-125. [PubMed: 23648438]

48. Mikuriya S, Saito T, Matsuba T, et al. Pathologic and immunologic analysis for a case with carcinoma of aberrant breast of the axilla showed "abscopal effect" after the radiotherapy (author's transl) [in Japanese]. Nihon Gan Chiryo Gakkai Shi. 1978; 13:406-413. [PubMed: 712167]

49. Rees GJ, Ross CM. Abscopal regression following radiotherapy for adenocarcinoma. Br J Radiol. 1983; 56:63-66. [PubMed: 6185172]

50. Nakanishi M, Chuma M, Hige S, et al. Abscopal effect on hepatocellular carcinoma. Am J Gastroenterol. 2008; 103:1320-1321. [PubMed: 18477367]

51. Cotter SE, Dunn GP, Collins KM, et al. Abscopal effect in a patient with metastatic Merkel cell carcinoma following radiation therapy: potential role of induced antitumor immunity. Arch Dermatol. 2011; 147:870-872. [PubMed: 21768497]

52. Ishiyama H, Teh BS, Ren H, et al. Spontaneous regression of thoracic metastases while progression of brain metastases after stereotactic radiosurgery and stereotactic body radiotherapy for metastatic renal cell carcinoma: abscopal effect prevented by the blood-brain barrier? Clin Genitourin Cancer. 2012; 10:196-198. [PubMed: 22409865] 
53. Takaya M, Niibe Y, Tsunoda S, et al. Abscopal effect of radiation on toruliform para-aortic lymph node metastases of advanced uterine cervical carcinoma-a case report. Anticancer Res. 2007; 27:499-503. [PubMed: 17348433]

54. Okuma K, Yamashita H, Niibe Y, et al. Abscopal effect of radiation on lung metastases of hepatocellular carcinoma: a case report. J Med Case Rep. 2011; 5:111. [PubMed: 21418591]

55. Liu Y, Xia T, Zhang W, et al. Variations of circulating endothelial progenitor cells and transforming growth factor-beta-1 (TGF-beta1) during thoracic radiotherapy are predictive for radiation pneumonitis. Radiat Oncol. 2013; 8:189. [PubMed: 23885707]

56. Persa E, Balogh A, Safrany G, et al. The effect of ionizing radiation on regulatory $\mathrm{T}$ cells in health and disease. Cancer Lett. 2015; 368:252-261. [PubMed: 25754816]

57. Vatner RE, Formenti SC. Myeloid-derived cells in tumors: effects of radiation. Semin Radiat Oncol. 2015; 25:18-27. [PubMed: 25481262]

58. Xu J, Escamilla J, Mok S, et al. CSF1R signaling blockade stanches tumor-infiltrating myeloid cells and improves the efficacy of radiotherapy in prostate cancer. Cancer Res. 2013; 73:27822794. [PubMed: 23418320]

59. Nikitina EY, Gabrilovich DI. Combination of gamma-irradiation and dendritic cell administration induces a potent antitumor response in tumor-bearing mice: approach to treatment of advanced stage cancer. Int J Cancer. 2001; 94:825-833. [PubMed: 11745485]

60. Kim KW, Kim SH, Shin JG, et al. Direct injection of immature dendritic cells into irradiated tumor induces efficient antitumor immunity. Int J Cancer. 2004; 109:685-690. [PubMed: 14999775]

61. Dewan MZ, Vanpouille-Box C, Kawashima N, et al. Synergy of topical toll-like receptor 7 agonist with radiation and low-dose cyclophosphamide in a mouse model of cutaneous breast cancer. Clin Cancer Res. 2012; 18:6668-6678. [PubMed: 23048078]

62. Twyman-Saint Victor C, Rech AJ, Maity A, et al. Radiation and dual checkpoint blockade activate non-redundant immune mechanisms in cancer. Nature. 2015; 520:373-377. [PubMed: 25754329]

63. Reits EA, Hodge JW, Herberts CA, et al. Radiation modulates the peptide repertoire, enhances MHC class I expression, and induces successful antitumor immunotherapy. J Exp Med. 2006; 203:1259-1271. [PubMed: 16636135]

64. Garg AD, Nowis D, Golab J, et al. Immunogenic cell death, DAMPs and anticancer therapeutics: an emerging amalgamation. Biochim Biophys Acta. 2010; 1805:53-71. [PubMed: 19720113]

65. Apetoh L, Ghiringhelli F, Tesniere A, et al. Toll-like receptor 4-dependent contribution of the immune system to anticancer chemotherapy and radio-therapy. Nat Med. 2007; 13:1050-1059. [PubMed: 17704786]

66. Shi Y, Evans JE, Rock KL. Molecular identification of a danger signal that alerts the immune system to dying cells. Nature. 2003; 425:516-521. [PubMed: 14520412]

67. Srivastava P. Roles of heat-shock proteins in innate and adaptive immunity. Nat Rev Immunol. 2002; 2:185-194. [PubMed: 11913069]

68. Hallahan D, Kuchibhotla J, Wyble C. Cell adhesion molecules mediate radiation-induced leukocyte adhesion to the vascular endothelium. Cancer Res. 1996; 56:5150-5155. [PubMed: 8912850]

69. Verstegen NE, Oosterhuis JW, Palma DA, et al. Stage I-II non-small-cell lung cancer treated using either stereotactic ablative radiotherapy (SABR) or lobectomy by video-assisted thoracoscopic surgery (VATS): outcomes of a propensity score-matched analysis. Ann Oncol. 2013; 24:15431548. [PubMed: 23425947]

70. Kwon ED, Drake CG, Scher HI, et al. Ipilimumab versus placebo after radiotherapy in patients with metastatic castration-resistant prostate cancer that had progressed after docetaxel chemotherapy (CA184-043): a multicentre, randomised, double-blind, phase 3 trial. Lancet Oncol. 2014; 15:700-712. [PubMed: 24831977]

71. Filatenkov A, Baker J, Mueller AM, et al. Ablative tumor radiation can change the tumor immune cell microenvironment to induce durable complete remissions. Clin Cancer Res. 2015; 21:37273739. [PubMed: 25869387]

72. Grills IS, Mangona VS, Welsh R, et al. Outcomes after stereotactic lung radiotherapy or wedge resection for stage I non-small-cell lung cancer. J Clin Oncol. 2010; 28:928-935. [PubMed: 20065181] 
73. Onishi H, Shirato H, Nagata Y, et al. Stereotactic body radiotherapy (SBRT) for operable stage I non-small-cell lung cancer: can SBRT be comparable to surgery? Int J Radiat Oncol Biol Phys. 2011; 81:1352-1358. [PubMed: 20638194]

74. Stinauer MA, Kavanagh BD, Schefter TE, et al. Stereotactic body radiation therapy for melanoma and renal cell carcinoma: impact of single fraction equivalent dose on local control. Radiat Oncol. 2011; 6:34. [PubMed: 21477295]

75. Rusthoven KE, Kavanagh BD, Burri SH, et al. Multi-institutional phase I/II trial of stereotactic body radiation therapy for lung metastases. J Clin Oncol. 2009; 27:1579-1584. [PubMed: 19255320]

76. Milano MT, Katz AW, Zhang H, et al. Oligometastases treated with stereo-tactic body radiotherapy: long-term follow-up of prospective study. Int J Radiat Oncol Biol Phys. 2012; 83:878-886. [PubMed: 22172903]

77. Lee MT, Kim JJ, Dinniwell R, et al. Phase I study of individualized stereo-tactic body radiotherapy of liver metastases. J Clin Oncol. 2009; 27:1585-1591. [PubMed: 19255313]

78. Demaria S, Golden EB, Formenti SC. Role of local radiation therapy in cancer immunotherapy. JAMA Oncol. 2015; 1:1325-1332. [PubMed: 26270858]

79. Grass GD, Krishna N, Kim S. The immune mechanisms of abscopal effect in radiation therapy. Curr Probl Cancer. 2016; 40:10-24. [PubMed: 26612692]

80. de la Cruz-Merino L, Illescas-Vacas A, Grueso-Lopez A, et al. Radiation for awakening the dormant immune system, a promising challenge to be explored. Front Immunol. 2014; 5:102. [PubMed: 24672524]

81. Sridharan V, Schoenfeld JD. Immune effects of targeted radiation therapy for cancer. Discov Med. 2015; 19:219-228. [PubMed: 25828526]

82. Park B, Yee C, Lee KM. The effect of radiation on the immune response to cancers. Int J Mol Sci. 2014; 15:927-943. [PubMed: 24434638]

83. Deng L, Liang H, Xu M, et al. STING-dependent cytosolic DNA sensing promotes radiationinduced type I interferon-dependent antitumor immunity in immunogenic tumors. Immunity. 2014; 41:843-852. [PubMed: 25517616]

84. Golden EB, Frances D, Pellicciotta I, et al. Radiation fosters dose-dependent and chemotherapyinduced immunogenic cell death. Oncoimmunology. 2014; 3:e28518. [PubMed: 25071979]

85. Gameiro SR, Jammeh ML, Wattenberg MM, et al. Radiation-induced immunogenic modulation of tumor enhances antigen processing and calreticulin exposure, resulting in enhanced T-cell killing. Oncotarget. 2014; 5:403-416. [PubMed: 24480782]

86. Golden EB, Pellicciotta I, Demaria S, et al. The convergence of radiation and immunogenic cell death signaling pathways. Front Oncol. 2012; 2:88. [PubMed: 22891162]

87. Akashi M, Hachiya M, Koeffler HP, et al. Irradiation increases levels of GM-CSF through RNA stabilization which requires an AU-rich region in cancer cells. Biochem Biophys Res Commun. 1992; 189:986-993. [PubMed: 1472071]

88. Kim JY, Son YO, Park SW, et al. Increase of NKG2D ligands and sensitivity to NK cell-mediated cytotoxicity of tumor cells by heat shock and ionizing radiation. Exp Mol Med. 2006; 38:474-484. [PubMed: 17079863]

89. Torihata H, Ishikawa F, Okada Y, et al. Irradiation up-regulates CD80 expression through two different mechanisms in spleen B cells, B lymphoma cells, and dendritic cells. Immunology. 2004; 112:219-227. [PubMed: 15147565]

90. Hellevik T, Martinez-Zubiaurre I. Radiotherapy and the tumor stroma: the importance of dose and fractionation. Front Oncol. 2014; 4:1. [PubMed: 24478982]

91. Ganss R, Ryschich E, Klar E, et al. Combination of T-cell therapy and trigger of inflammation induces remodeling of the vasculature and tumor eradication. Cancer Res. 2002; 62:1462-1470. [PubMed: 11888921]

92. Matsumura S, Wang B, Kawashima N, et al. Radiation-induced CXCL16 release by breast cancer cells attracts effector T cells. J Immunol. 2008; 181:3099-3107. [PubMed: 18713980]

93. Garnett CT, Palena C, Chakraborty M, et al. Sublethal irradiation of human tumor cells modulates phenotype resulting in enhanced killing by cytotoxic T lymphocytes. Cancer Res. 2004; 64:79857994. [PubMed: 15520206] 
94. Chakraborty M, Abrams SI, Camphausen K, et al. Irradiation of tumor cells up-regulates Fas and enhances CTL lytic activity and CTL adoptive immunotherapy. J Immunol. 2003; 170:6338-6347. [PubMed: 12794167]

95. Schaue D, Ratikan JA, Iwamoto KS, et al. Maximizing tumor immunity with fractionated radiation. Int J Radiat Oncol Biol Phys. 2012; 83:1306-1310. [PubMed: 22208977]

96. Shields LB, Shelton BJ, Shearer AJ, et al. Dexamethasone administration during definitive radiation and temozolomide renders a poor prognosis in a retrospective analysis of newly diagnosed glioblastoma patients. Radiat Oncol. 2015; 10:222. [PubMed: 26520780]

97. Pitter KL, Tamagno I, Alikhanyan K, et al. Corticosteroids compromise survival in glioblastoma. Brain. 2016; 139:1458-1471. [PubMed: 27020328]

98. Lee Y, Auh SL, Wang Y, et al. Therapeutic effects of ablative radiation on local tumor require $\mathrm{CD}^{+} \mathrm{T}$ cells: changing strategies for cancer treatment. Blood. 2009; 114:589-595. [PubMed: 19349616]

99. Lugade AA, Moran JP, Gerber SA, et al. Local radiation therapy of B16 melanoma tumors increases the generation of tumor antigen-specific effector cells that traffic to the tumor. $\mathrm{J}$ Immunol. 2005; 174:7516-7523. [PubMed: 15944250]

100. Verbrugge I, Hagekyriakou J, Sharp LL, et al. Radiotherapy increases the permissiveness of established mammary tumors to rejection by immunomodulatory antibodies. Cancer Res. 2012; 72:3163-3174. [PubMed: 22570253]

101. Trowell OA. The sensitivity of lymphocytes to ionising radiation. J Pathol Bacteriol. 1952; 64:687-704. [PubMed: 13000583]

102. Crittenden MR, Cottam B, Savage T, et al. Expression of NF-kappaB p50 in tumor stroma limits the control of tumors by radiation therapy. PLoS One. 2012; $7:$ e39295. [PubMed: 22761754]

103. Tsai CS, Chen FH, Wang CC, et al. Macrophages from irradiated tumors express higher levels of iNOS, arginase-I and COX-2, and promote tumor growth. Int J Radiat Oncol Biol Phys. 2007; 68:499-507. [PubMed: 17398016]

104. Ahn GO, Tseng D, Liao CH, et al. Inhibition of Mac-1 (CD11b/CD18) enhances tumor response to radiation by reducing myeloid cell recruitment. Proc Natl Acad Sci U S A. 2010; 107:83638368. [PubMed: 20404138]

105. Barcellos-Hoff MH, Park C, Wright EG. Radiation and the microenvironment-tumorigenesis and therapy. Nat Rev Cancer. 2005; 5:867-875. [PubMed: 16327765]

106. Fridman WH, Pages F, Sautes-Fridman C, et al. The immune contexture in human tumours: impact on clinical outcome. Nat Rev Cancer. 2012; 12:298-306. [PubMed: 22419253]

107. Deng L, Liang H, Burnette B, et al. Irradiation and anti-PD-L1 treatment synergistically promote antitumor immunity in mice. J Clin Invest. 2014; 124:687-695. [PubMed: 24382348]

108. Curran MA, Montalvo W, Yagita H, et al. PD-1 and CTLA-4 combination blockade expands infiltrating $\mathrm{T}$ cells and reduces regulatory $\mathrm{T}$ and myeloid cells within B16 melanoma tumors. Proc Natl Acad Sci U S A. 2010; 107:4275-4280. [PubMed: 20160101]

109. Duraiswamy J, Freeman GJ, Coukos G. Therapeutic PD-1 pathway blockade augments with other modalities of immunotherapy T-cell function to prevent immune decline in ovarian cancer. Cancer Res. 2013; 73:6900-6912. [PubMed: 23975756]

110. Kioi M, Vogel H, Schultz G, et al. Inhibition of vasculogenesis, but not angiogenesis, prevents the recurrence of glioblastoma after irradiation in mice. J Clin Invest. 2010; 120:694-705. [PubMed: 20179352]

111. Demaria S, Kawashima N, Yang AM, et al. Immune-mediated inhibition of metastases after treatment with local radiation and CTLA-4 blockade in a mouse model of breast cancer. Clin Cancer Res. 2005; 11:728-734. [PubMed: 15701862]

112. Liang H, Deng L, Chmura S, et al. Radiation-induced equilibrium is a balance between tumor cell proliferation and T cell-mediated killing. J Immunol. 2013; 190:5874-5881. [PubMed: 23630355]

113. Tsai MH, Cook JA, Chandramouli GV, et al. Gene expression profiling of breast, prostate, and glioma cells following single versus fractionated doses of radiation. Cancer Res. 2007; 67:38453852. [PubMed: 17440099] 
114. Xie J, Wang Y, Freeman ME 3rd, et al. Beta 2-microglobulin as a negative regulator of the immune system: high concentrations of the protein inhibit in vitro generation of functional dendritic cells. Blood. 2003; 101:4005-4012. [PubMed: 12531797]

115. Burks J, Reed RE, Desai SD. Free ISG15 triggers an antitumor immune response against breast cancer: a new perspective. Oncotarget. 2015; 6:7221-7231. [PubMed: 25749047]

116. Reich NC. A death-promoting role for ISG54/IFIT2. J Interferon Cytokine Res. 2013; 33:199205. [PubMed: 23570386]

117. He S, Wang L, Wu Y, et al. CCL3 and CCL20-recruited dendritic cells modified by melanoma antigen gene-1 induce anti-tumor immunity against gastric cancer ex vivo and in vivo. J Exp Clin Cancer Res. 2010; 29:37. [PubMed: 20420712]

118. Martin-Orozco N, Muranski P, Chung Y, et al. T helper 17 cells promote cytotoxic T cell activation in tumor immunity. Immunity. 2009; 31:787-798. [PubMed: 19879162]

119. Hiniker SM, Chen DS, Knox SJ. Abscopal effect in a patient with melanoma. N Engl J Med. 2012; 366:2035. author reply 2036. [PubMed: 22621637]

120. Golden EB, Demaria S, Schiff PB, et al. An abscopal response to radiation and ipilimumab in a patient with metastatic non-small cell lung cancer. Cancer Immunol Res. 2013; 1:365-372. [PubMed: 24563870]

121. Thallinger C, Prager G, Ringl H, et al. Abscopal effect in the treatment of malignant melanoma [in German]. Der Hautarzt; Zeitschrift fur Dermatologie, Venerologie, und verwandte Gebiete. 2015; 66:545-548.

122. Wersäll PJ, Blomgren $\mathrm{H}$, Pisa $\mathrm{P}$, et al. Regression of non-irradiated metastases after extracranial stereotactic radiotherapy in metastatic renal cell carcinoma. Acta Oncol. 2006; 45:493-497. [PubMed: 16760190]

123. Seung SK, Curti BD, Crittenden M, et al. Phase 1 study of stereotactic body radiotherapy and interleukin-2 - tumor and immunological responses. Science translational medicine. 2012; 4:137ra74.

124. Poleszczuk JT, Luddy KA, Prokopiou S, et al. Abscopal benefits of localized radiotherapy depend on activated T-cell trafficking and distribution between metastatic lesions. Cancer Res. 2016; 76:1009-1018. [PubMed: 26833128]

125. Slovin SF, Higano CS, Hamid O, et al. Ipilimumab alone or in combination with radiotherapy in metastatic castration-resistant prostate cancer: results from an open-label, multicenter phase I/II study. Ann Oncol. 2013; 24:1813-1821. [PubMed: 23535954]

126. Chad Tang, AN., de Groot Patricia, Joe, Chang, et al. Preliminary phase I results of ipilimumab and stereotactic radiation targeting liver or lung lesions in a heavily treated population of metastatic patients. Presented at ASTRO; San Antonio, TX. 2015.

127. Chimeric antigen receptor-modified $\mathrm{T}$ cells in chronic lymphoid leukemia; chimeric antigen receptor-modified $\mathrm{T}$ cells for acute lymphoid leukemia; chimeric antigen receptor $\mathrm{T}$ cells for sustained remissions in leukemia. N Engl J Med. 2016; 374:998.

128. Grupp SA, Kalos M, Barrett D, et al. Chimeric antigen receptor-modified T cells for acute lymphoid leukemia. N Engl J Med. 2013; 368:1509-1518. [PubMed: 23527958]

129. Gill S, June CH. Going viral: chimeric antigen receptor T-cell therapy for hematological malignancies. Immunol Rev. 2015; 263:68-89. [PubMed: 25510272]

130. Stojdl DF, Lichty B, Knowles S, et al. Exploiting tumor-specific defects in the interferon pathway with a previously unknown oncolytic virus. Nat Med. 2000; 6:821-825. [PubMed: 10888934]

131. Chiocca EA, Rabkin SD. Oncolytic viruses and their application to cancer immunotherapy. Cancer Immunol Res. 2014; 2:295-300. [PubMed: 24764576]

132. Melero I, Gaudernack G, Gerritsen W, et al. Therapeutic vaccines for cancer: an overview of clinical trials. Nat Rev Clin Oncol. 2014; 11:509-524. [PubMed: 25001465]

133. Guo C, Manjili MH, Subjeck JR, et al. Therapeutic cancer vaccines: past, present, and future. Adv Cancer Res. 2013; 119:421-475. [PubMed: 23870514] 


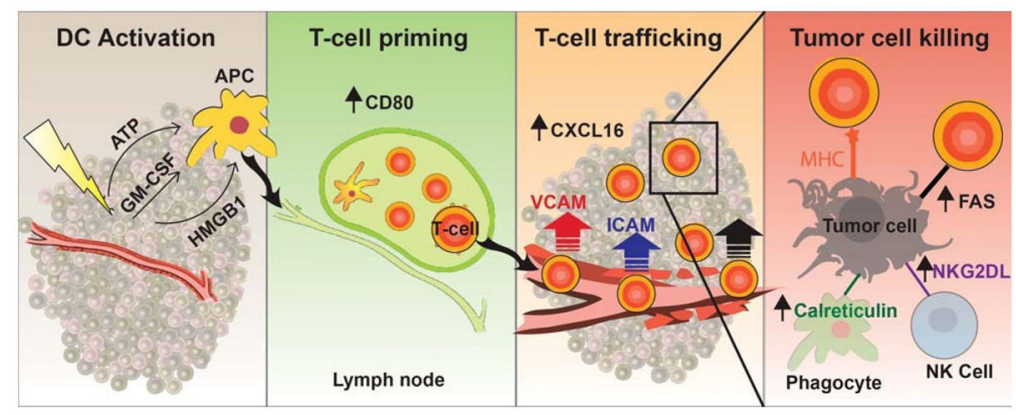

FIGURE 1.

Radiation triggers the release of various factors from the tumor and surrounding tissue, including adenosine triphosphate, granulocyte-macrophage colony-stimulating factor, and high mobility group box 1 protein. These factors constitute immunogenic cell death, which allow the APCs to become activated and then migrate to the lymph node. Once at the lymph node, APCs have increased expression of CD80, resulting in T-cell activation. These T cells are then able to traffic back to the tumor through increased expression of CXCL16 by the tumor and ICAM and VCAM expression by the endothelial cells. Increased expression of MHC I, calreticulin, Fas, and NKG2D ligands on tumor cells allows immune cells to kill tumor cells. APCs indicate antigen-presenting cells. ATP, adenosine triphosphate; GM-CSF, granulocyte-macrophage colony-stimulating factor; HMGB1, high mobility group box 1 protein; APC, antigen-presenting cell; ICAM, intercellular adhesion molecule; VCAM, vascular cell adhesion molecule; MHC I, major histocompatibility complex type I. 


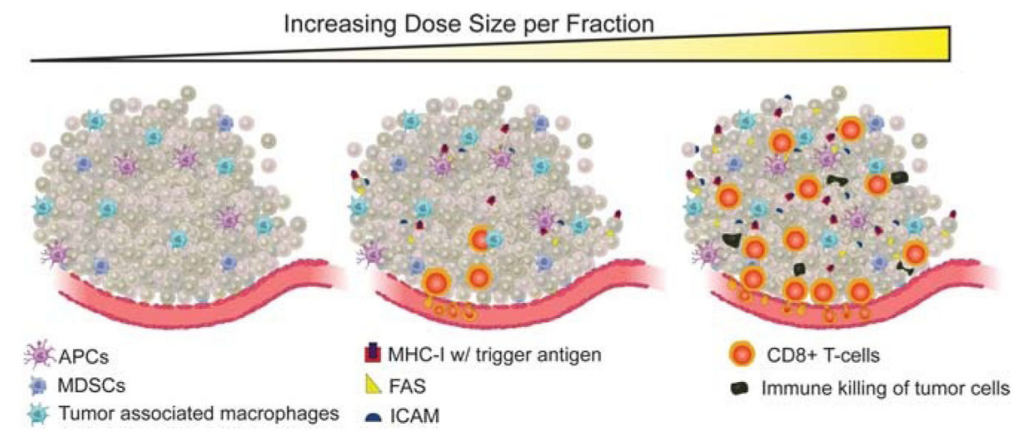

FIGURE 2.

There appears to be a dose-dependent increase in tumor immunogenicity and radiation dose size per fraction. Higher dose size per fraction results in greater infiltration of tumors by $\mathrm{CD}^{+} \mathrm{T}$ cells as well as higher levels of ICAM, Fas, and MHC-I with loaded tumor antigen expressed on the tumor cells surface. These higher levels of expression, as a function of higher radiation dose size, correlate with improved antitumor immune-directed killing. APC, antigen-presenting cell; ICAM, intercellular adhesion molecule; MHC I, major histocompatibility complex type I; MDSC, myeloid-derived suppressor cell. 

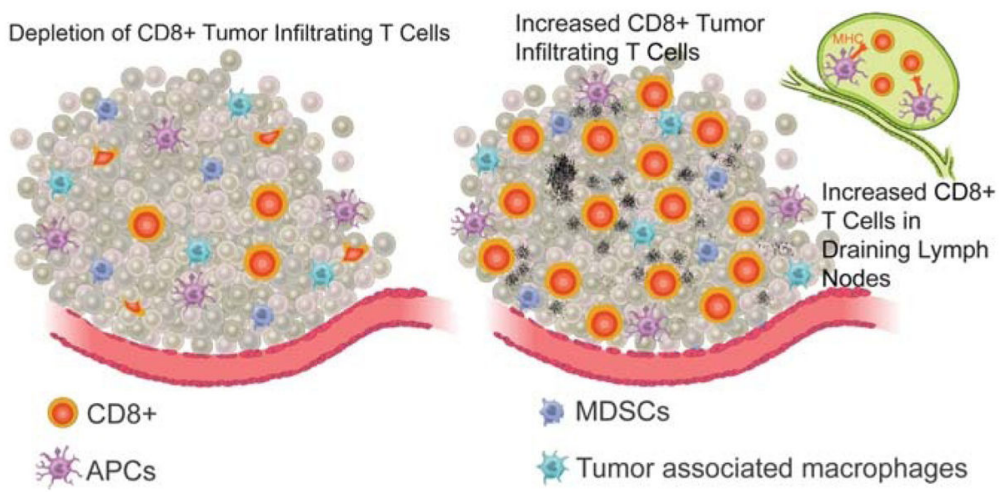

FIGURE 3.

Stereotactic body radiotherapy-like regimens appear to be more immunogenic than lowerdose, or conventional, fractionated regimens in preclinical studies. Stereotactic body radiotherapy-like regimens (right) result in greater infiltration of $\mathrm{CD}^{+} \mathrm{T}$ cells in tumor and draining lymph nodes, as well as antigen-presenting cells in draining lymph nodes. This immune infiltration correlates with greater immune-directed tumor destruction, control, and survival. Lower-dose, or conventional, fractionated regimens (left) result in relatively less robust immune infiltration and, when radiation is prolonged for multiple weeks on end, may have immune-depleting effects, particularly on anti-tumor-infiltrating $\mathrm{CD} 8^{+} \mathrm{T}$ cells, as well as increased recruitment of myeloid derived suppressor cells. APC, antigen-presenting cell; MDSC, myeloid-derived suppressor cell. 